\title{
Regeneration of neuronal cell types in Schmidtea mediterranea: an immunohistochemical and expression study
}

\author{
SUSANNA FRAGUAS, SARA BARBERÁN, BEGOÑA IBARRA, LINDA STÖGER and FRANCESC CEBRIÀ* \\ Departament de Genètica, Facultat de Biologia, Universitat de Barcelona and \\ Institut de Biomedicina de la Universitat de Barcelona (IBUB), Universitat de Barcelona, Barcelona, Spain
}

\begin{abstract}
Freshwater planarians are unique in their ability to regenerate a complete Central Nervous System (CNS) from almost any small piece of their body in just a few days. The planarian CNS contains a pair of anterior cephalic ganglia lying on top of two ventral nerve cords that extend along the length of the animal. Studies of planarian CNS regeneration have generally used pan-neural markers, which provide only a general overview of the process. Nevertheless, some reports have started to characterize the genes that are required for this process. In this study, to obtain a more detailed description of planarian neural regeneration, we monitored the regeneration of neuronal populations specifically labelled with antibodies against serotonin, allatostatin, neuropeptide $F$, GYRFamide and FMRFamide. We also characterized the regeneration of dopaminergic and octopaminergic cell populations by in situ hybridization. Finally, we characterized the expression pattern of a set of receptors for neurotransmitters, neuropeptides and hormones that are suggested to play a role in the regeneration process itself. Together, these data provide a more detailed description of the cellular events occurring during anterior and posterior CNS regeneration in planarians and provide the foundations for future mechanistic studies into the regeneration process in this important model system.
\end{abstract}

KEY WORDS: planaria, regeneration, nervous system, neurotransmitter, neuronal cell type

\section{Introduction}

In contrast to most model organisms, including those with some regenerative capabilities, freshwater planarians are unique in their capacity to regenerate an organized and functional Central Nervous System (CNS) de novo from a small body piece within just a few days (reviewed in Cebrià, 2007; Agata and Umesono, 2008). The planarian CNS is mainly formed by an anterior brain and a pair of ventral nerve cords (VNC) that run from the head to the tip of the tail and are interconnected by transverse commissures. The brain consists of two lobed arch-shaped cephalic ganglia connected by a single anterior commissure and can be structurally divided into a central spongy region (neuropil) and several lateral branches that project towards the periphery of the head (Agata et al., 1998; Cebrià et al., 2002a). Although at first glance the planarian CNS seems morphologically simple, it exhibits substantial molecular, cellular and genetic complexity. Initial studies by Umesono et al., $(1997,1999)$ showed that otd/Otx-related homebox genes are conserved in Dugesia japonica and are expressed in distinct non-overlapping domains within the cepahlic ganglia: $\operatorname{DjotxA}$ is expressed in the medial region of the cephalic ganglia, DjotxB labels the central spongy region and Djotp is detected in the lateral branches that project towards the periphery of the head (Umesono et al., 1999). Subsequent studies showed that the planarian CNS can be further compartmentalized based on the expression of a set of neural-specific genes (Cebrià et al., 2002b). Moreover, since planarian neural genes display a high level of conservation and similarity with their homologues in vertebrates, planarians are also a suitable model in which to study the evolutionary history of the CNS (Mineta et al., 2003).

Although several genes are now known to be required for proper regeneration of the planarian CNS (Cebrià and Newmark 2005, 2007; Cebrià et al., 2007; Fusaoka et al., 2006; Higuchi et al., 2008; Inoue et al., 2007; Kobayashi et al., 2007), we are still far away from fully understanding how the nervous system is reconstructed after amputation. During regeneration, newly formed neurons differentiate from pluripotent stem cells called neoblasts (Baguña et

Abbreviations used in this paper: 5F10, allatostatin; 5-HT, serotonin; CNS, Central Nervous System; NPF, neuropeptide F; VNC, ventral nerve cord.

\footnotetext{
*Address correspondence to: Francesc Cebrià. Departament de Genètica, Facultat de Biologia, Av. Diagonal 643, Edifici annex planta 1, 08028 Barcelona, Catalunya, Spain. Tel: +34-93-403-5301. Fax: +34-93-403-4420. e-mail: fcebrias@ub.edu - web: http://www.ub.edu/planaria
} 
al., 1989a; Wagner et al., 2011). However, many questions are still unresolved, such as how neoblasts become committed to a neural cell fate, how the new neurons are organized to form a properly patterned brain, and how the newly regenerated brain is integrated into the pre-existing nervous system. In order to address some of these questions, a large set of specific markers for distinct neuronal populations will be required. Recently, several neuronal subpopulations have been characterized immunohistochemically in the model species Schmidtea mediterranea (Cebrià, 2008). However, that study focused on intact non-regenerating planarians. Here, we use the same antibodies to analyze how different neuronal cell types appear during regeneration of the anterior (differentiation of the new cephalic ganglia and growth of the truncated nerve cords) and posterior (growth of the truncated nerve cords) CNS. In addition, we characterize the regeneration of dopaminergic and octopaminergic neurons by in situ hybridization. The markers used here correspond to a classical neurotransmitter (serotonin), neuropeptides (neuropeptide F, FMRFamide, GYRFamide, allatostatin) and enzymes required for the synthesis of neurotransmitters such as dopamine or octopamine. Although there is not much information about the role these neurotransmitters and neuropeptides could play during planarian regeneration some papers have suggested that: serotonin may promote neoblast proliferation and regeneration (Franquinet 1979; Franquinet and Le Moigne, 1979), dopaminergic neurons may have a function in planarian locomotion (Nishimura et al., 2007b), and NPF and FMRFamide may be important to promote the regeneration of the pharynx (Kreshchenko, 2008; Kreshchenko et al., 2008). Finally, to begin to address the pro-

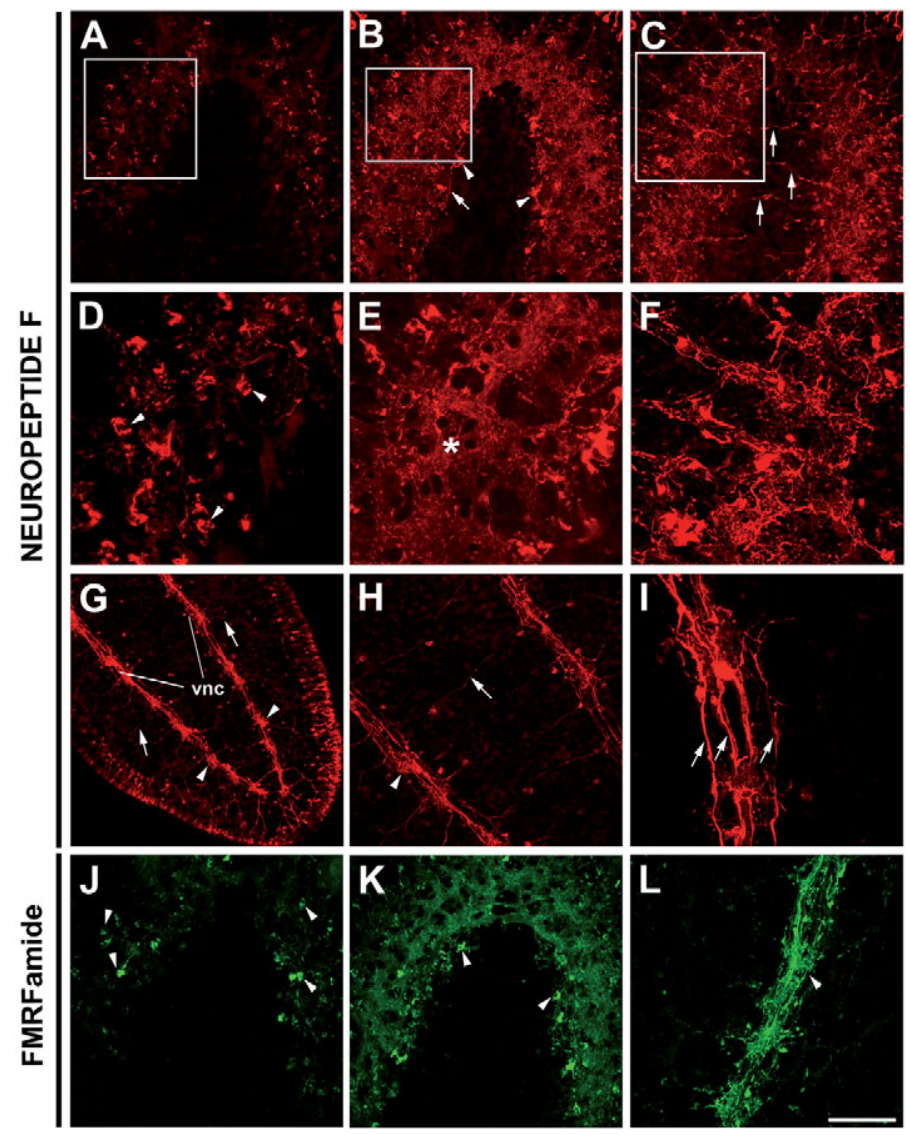

posed role of some of these factors in the regenerative process (Baguñà et al., 1989b; Cebrià, 2007), we have characterized the expression pattern of putative receptors for neurotransmitters, peptides and hormones in S. mediterranea (Abril et al., 2010) in intact and regenerating planarians.

\section{Results}

\section{General structure of the Central Nervous System in S. mediterranea}

Planarian cephalic ganglia contain a central neuropil surrounded by most of the neuronal cell bodies (Agata et al., 1998; Cebria, 2008; Okamoto et al., 2005). Immunohistochemistry with antibodies against Neuropeptide F (NPF; Maule et al., 1992) and FMRFamide labelled the neuropil and also individual cells at specific locations within it (Fig. 1). Scattered tear-shaped neurons were observed in the dorsal region of the cephalic ganglia following anti-NPF immunostaining in intact animals (Fig.1 A,D). The central neuropil was seen with its typical spongy structure (Fig. $1 \mathrm{~B}, \mathrm{E}$ ). In addition, NPF-positive cells with long processes were observed along the medial region of the cephalic ganglia (arrowheads in Fig. 1B). The anti-NPF antibody also labelled the ventral nerve cords (VNCs) all along the body (Fig. $1 \mathrm{G}, \mathrm{H}, \mathrm{I}$ ). Ganglia-like knots were observed along the VNCs (arrowheads in Fig. $1 \mathrm{G}, \mathrm{H}$ ). From these ganglia, lateral processes projected towards the body margin (arrows in Fig. 1G) and transverse commissures connected both nerve cords (arrows in Fig. 1H). After anti-NPF immunostaining the ganglia-like knots along the VNCs appeared to be connected by individual axon bundles (arrows in Fig. 1I).

Immunostaining with an anti-FMRFamide antibody showed a similar pattern to that described for the anti-NPF antibody. Thus, FMRFamide-positive cells were observed in the dorsal region of the cephalic ganglia (Fig. 1J) as well as along the medial part of the central neuropil (arrowheads in Fig. 1K). This anti-FMRFamide

Fig. 1. General structure of the Schmidtea mediterranea Central Nervous System. Whole-mount immunohistochemistry of the planarian central nervous system with anti-NPF (A-I) and anti-FMRFamide (J-L) antibodies. (A-C) Projections of different confocal planes of the same sample, going from dorsal(A) to ventral(C). (A) Dorsal-most region of the cephalic ganglia. (B) Central neuropil. Arrowheads point to individual cells along the medial region. Arrow points to fibres projecting from these cells. (C) Anterior ventral nerve cords below the cephalic ganglia. Arrows indicate the transverse commissures connecting left and right cords. (D-F) Higher magnifications of boxed areas in (A-C), respectively. Arrowheads in (D) point to individual dorsal cells. Asterisk in (E) marks the central neuropil with its characteristic spongy structure. $(\mathbf{G}, \mathbf{H})$ Posterior ventral nerve cords (vnc). Arrowheads in $(G, H)$ point to the ganglia-like knots distributed along the nerve cords. Arrows in $(G, H)$ point to lateral projections and transverse commissures connecting left and right nerve cords, respectively. The signal observed along the body margin in (G) corresponds to un-specific background staining. (I) Detailed view of the individual axon bundles (arrows) that connect the ganglia-like knots along the nerve cords. $(\mathbf{J}, \mathbf{K})$ Projections of different confocal planes of the same sample, going from dorsal (J) to ventral (K). (J) Arrowheads point to individual cells on the dorsal-most region of the cephalic ganglia. (K) Central spongy neuropil. Arrowheads point to cells in the medial region. (L) Ventral nerve cord constituted by more compacted axon bundles (arrowhead) compared to the anti-NPF pattern. In (A-F, I-K) anterior is to the top; in $(G, H)$ anterior is to the top left; in $(L)$ anterior is to the top right. Scale bars, $A, B, C, J, K, H, L, 100 \mu \mathrm{m} ; G, 200 \mu \mathrm{m} ; D, E, F, I, 50 \mu \mathrm{m}$. 


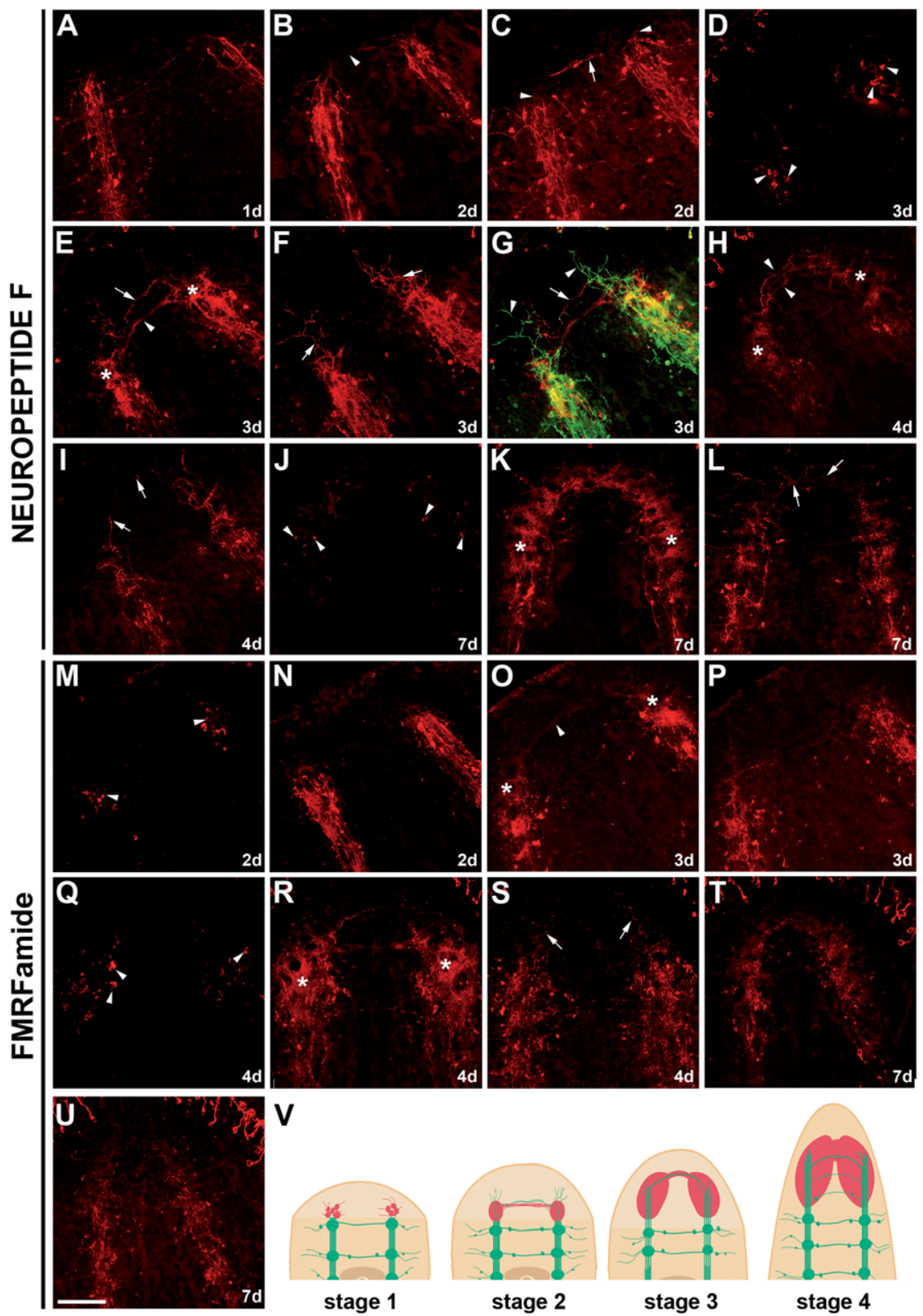

Fig. 2. Regeneration of the anterior Central Nervous System. (A-L) Anti-NPF immunostaining. (M-U) AntiFMRFamide immunostaining. All samples correspond to trunk fragments regenerating a new head. (A) Truncated nerve cords at day 1 of regeneration. (B,C) Projections of different confocal planes of the same sample at day 2 of regeneration, going from dorsal (B) to ventral (C). Arrowhead in (B) points to a fine fibre connecting the two dorsal developing cephalic ganglia. (C) Arrowheads point to fine fibres sprouting from the truncated ventral nerve cords. An arrow points to a transverse commissure connecting left and right cords. (D-F) Projections of different confocal planes of the same sample at day 3 of regeneration, going from dorsal (D) to ventral (F). (D) Accumulation of individual NPF-positive cells (arrowheads) in the dorsal-mostregion of the regenerating cephalic ganglia. (E) A commissure (arrowhead) connecting the cephalic ganglia. Anterior to the commissure, a fine fibre (arrow) connects the nerve cords (see also G). (F) Arrows point to fine fibres sprouting anteriorly from the ventral nerve cords. (G) Confocal projection of planes included in (E) and (F) pseudo-coloured in red and green, respectively, to show that the fine anterior fibre (arrow, in red) connects to fibres sprouting from the ventral nerve cords (arrowheads, in green). (H,I) Projections of different confocal planes of the same sample at day 4 of regeneration, going from dorsal (H) to ventral (I). (H) Asterisks mark the new spongy cephalic ganglia connected by an anterior commissure (arrowheads). (I) Fine fibres sprouting from the ventral nerve cords cross the midline and project contralaterally (arrows). (J-L) Projections of different confocal planes of the same sample at day 7 of regeneration, going from dorsal (J) to ventral (L). (J) Several NPF-positive cells are observed in the dorsal-most region of the cephalic ganglia (arrowheads). (K) The new neuropil shows its typical spongy structure (asterisks). (L) Arrows point to fine fibres from the ventral nerve cords below the anterior commissure. (M,N) Projections of different confocal planes of the same sample at 2 days of regeneration, going from dorsal (M) to ventral (N). (M) Arrowheads point to FMRFamidepositive cells dorsal to the cut ends of the ventral nerve cords. (N) Truncated nerve cords. (O,P) Projections of different confocal planes of the same sample at 3 days of regeneration, going from dorsal $(O)$ to ventral $(P)$. (O) Arrowhead points to a transverse fibre connecting the developing left and right cephalic ganglia (asterisks). (P)

Ventral nerve cords below them. (Q-S) Projections of different confocal planes of the same sample at 3 days of regeneration, going from dorsal (Q) to ventral (S). (Q) Dorsal FMRFamide-positive cells (arrowheads). (R) Regenerated cephalic ganglia (asterisks). (S) Arrows point to fibres sprouting from the ventral nerve cords. $(\mathbf{T}, \mathbf{U})$ Projections of different confocal planes of the same sample at 3 days of regeneration, going from dorsal $(T)$ to ventral (U). (T) Cephalic ganglia. (U) Ventral nerve cords. (V) Schematic model of the regeneration of the anterior central nervous system. Cephalic ganglia are represented in red and ventral nerve cords in green. Stage 1: 1-2 days of regeneration; stage 2: 2-3 days of regeneration; stage 3: 4 days of regeneration; stage 4: 7 days of regeneration. In $(A-I, M-P)$ anterior is to the top left; in $(K, L, Q-U)$ anterior is to the top. Scale bar, $100 \mu \mathrm{m}$.

antibody also labelled the VNCs; however, unlike with anti-NPF, the axon bundles connecting the ganglia-like knots appeared much more compact (arrowhead in Fig. 1L).

\section{Immunohistochemistry with anti-NPF and anti-FMRFamide during regeneration of the anterior Central Nervous System}

Recently, several neuronal subpopulations have been described in the most commonly used planarian species, $S$. mediterranea and D. japonica (Cebrià, 2008; Nishimura et al., 2007a, 2007b, 2008a, 2008b; Fraguas et al., 2011). In the case of D. Japonica, those studies included the characterization of distinct neuronal subpopulations in intact animals as well as how they re-appear during regeneration (Nishimura et al., 2007b, 2008c). However, while several specific neuronal types have been characterized in intact $S$. mediterranea (Cebrià, 2008; Collins et al., 2010), less information is available on how these cell types regenerate. In order to bridge this gap in information, we performed immunohistochemistry with several antibodies at different stages of regeneration (Figs. 2, 3, 4).

Anti-NPF immunostaining revealed truncated VNCs in the stump region after 1 day of regeneration (Fig. 2A). Two days after cutting, 
thin transverse processes probably connecting the developing dorsal cephalic ganglia were observed (arrowheads in Fig. 2B). At this stage, the nerve cords below the new cephalic ganglia extended some processes anteriorly (arrowheads in Fig. 2C) and transverse commissures connected them at their most anterior end (arrow in Fig. 2C). At day 3 of regeneration, clusters of NPF-positive cells appeared in the dorsal region of the regenerating cephalic ganglia (arrowheads in Fig. 2D) and the spongy structure of the new neuropil could be distinguished (asterisks in Fig. 2E). At this stage, a relatively thick commissure connected the cephalic ganglia (arrowhead in Fig. 2E). In addition, sprouts from the truncated VNCs were evident at this stage (arrows in Fig. 2F). In fact, axonal processes from these ventral cords extended anteriorly beyond the growing cephalic ganglia (arrowheads in Fig. 2G). Some of these processes actually turned to cross the midline in more dorsal regions (arrows in Fig. 2 E,G). At 4 days of regeneration, the new cephalic ganglia showed its typical spongy structure and bilobed organization (asterisks in Fig. $2 \mathrm{H}$ ); the two halves were clearly connected by a transverse commissure (indicated by arrowheads in Fig. $2 \mathrm{H}$ ). The regenerated VNCs were also evident below the cephalic ganglia (Fig. 2l). As seen at 3 days of regeneration, some
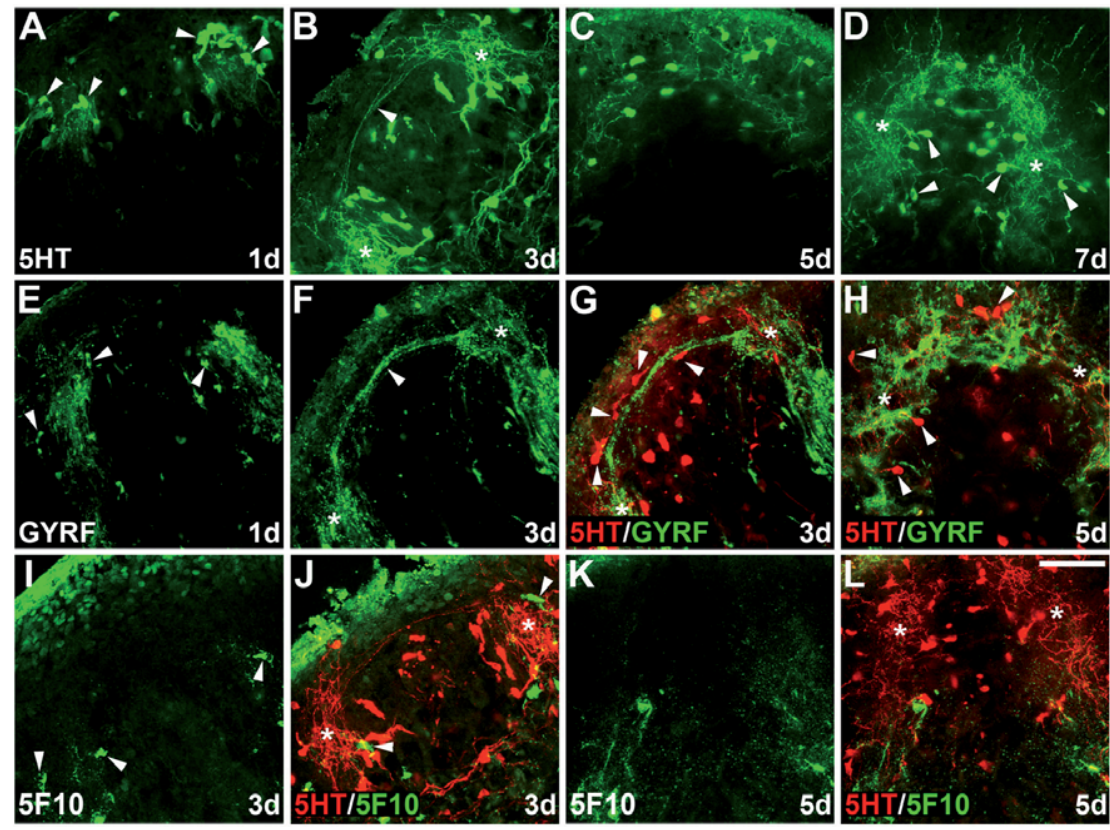

Fig. 3. Regeneration of the anterior Central Nervous System. (A-H) Anti-5-HT immunostaining. All samples correspond to trunk fragments regenerating a new head. (A) Arrowheads point to 5-HT-positive cells at the level of the truncated nervous system at day 1 of regeneration. (B) At day 3, a thin fibre (arrowhead) connects the developing cephalic ganglia (asterisks). (C) Five days of regeneration. (D) Seven-day regenerated cephalic ganglia with a central neuropil (asterisks) and peripheral cell bodies (arrowheads). (E-H) Anti-GYRFamide immunostaining. (E) Arrowheads point to GYRFamide-positive cells at the level of the truncated nervous system at day 1 of regeneration. (F) Developing cephalic ganglia (asterisks) connected by a thin commissure (arrowhead in F) at day 3 of regeneration. (G) Double immunostaining with anti-5-HT (in red). Arrowheads point to 5-HT-positive cells. Asterisks point to the cephalic ganglia. (H) Double immunostaining with anti-5-HT (in red) at day 5 of regeneration. Arrowheads indicate 5-HT-positive cells surrounding the central neuropil (asterisks). (I-L) Anti-5F10 (allatostatin) immunostaining. (J,L) Double immunostaining with anti-5-HT (in red). Arrowheads in (I,J) point to 5F10-positive cells. Asterisks in $(\mathrm{J}, \mathrm{L})$ mark the developing cephalic ganglia. In $(A, B, F, G, I, J)$ anterior is to the top left; in $(C, D, E, H, K, L)$ anterior is to the top. Scale bar, $100 \mu \mathrm{m}$. of the axonal processes from the VNCs projected contralaterally over the anterior commissure that connects the two halves of the anglia showed a pattern clearly resembling that of the

missure (arrows in Fig. 2L). anti-NPF, although slightly delayed (Fig. $2 \mathrm{M}-\mathrm{U}$ ). At 2 days of regeneration, an accumulation of FMRFamide-positive cells (arprocesses were observed connecting the left and righthalves of the CNS. Three days after amputation, new spongy cephalic ganglia (asterisks in Fig. 2O) appeared connected by a commissure (arrowhead in Fig. 2O). Regenerated VNCs were seen below these (Fig. 2P). At 4 days of regeneration, the number of dorsal positive cells increased (arrowheads in
Fig. 2Q), the spongy structure of the regenerated neuropil was more evident (asterisks in Fig. 2R) and thin axonal processes from the regenerating VNCs extended quite anteriorly (arrows in Fig. 2S). Finally, at 7 days of regeneration the new cephalic ganglia (Fig. 2T) and VNCs (Fig. 2U) below them showed a fully differentiated pattern.

\section{Dynamics of regeneration of cell populations la belled by anti-5-HT, anti-GYRFamide and anti-al- latostatin in the anterior Central Nervous System}

Recently, antibodies against GYRFamide, serotonin $(5-\mathrm{HT})$ and allatostatin $(5 \mathrm{~F} 10)$ were found to label distinct neuronal subpopulations in nonoverlapping cells in the intact planarian CNS (Cebrià, 2008). Here, we addressed how these different cell types re-appeared during regeneration. At day 1 of regeneration, 5-HT-positive cells were seen at the level of the truncated nerve cords (arrowheads in Fig. 3A). After 3 days, bundles of axonal processes were observed at the level of the differentiating cephalic ganglia (asterisks in Fig. 3 B,G). A few thin processes also connected the left and right sides (arrowhead in Fig. 3B). Five days after amputation, 5-HT-positive cells and thin processes gave rise to the typical arch-shaped brain (Fig. $3 \mathrm{C}, \mathrm{H}$ ). Finally, at day 7 of regeneration, the pattern of serotonergic neurons in the new cephalic ganglia (Fig. 3D) resembled the one in intact planarians, with most cell bodies (arrowheads in Fig. 3D) surrounding the central neuropil (asterisks in Fig. 3D).

At day 1 of regeneration, some GYRFamidepositive cells were also observed close to the amputation plane of the truncated VNCs (arrowheads in Fig. 3E). Three days after amputation, an anterior commissure (arrowhead in Fig. 3F) connected the two new cephalic ganglia (asterisks in Fig. 3F). 

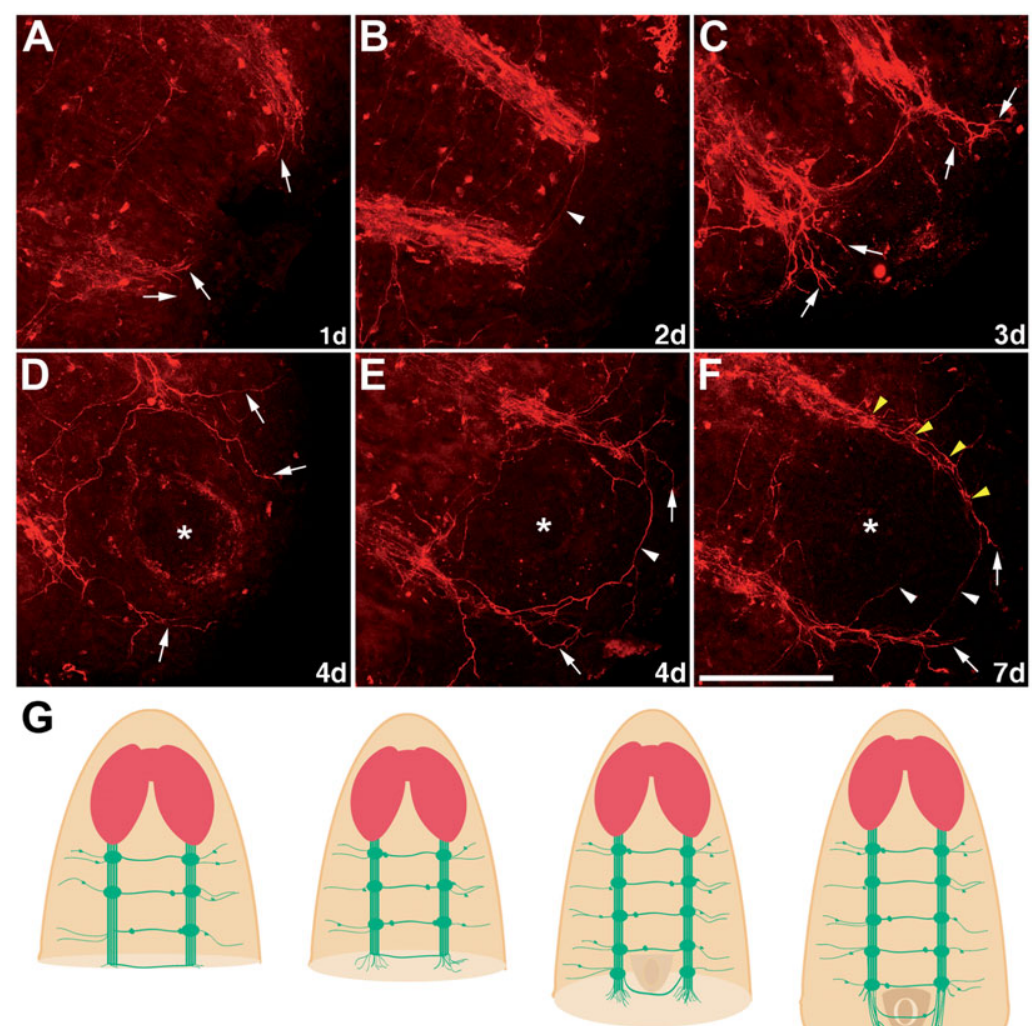

stage 1

stage 2

stage 3

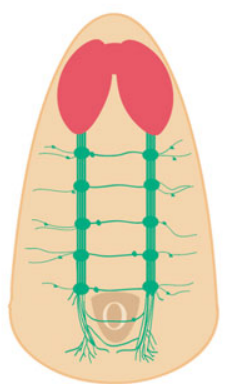

stage 4

Fig. 4. Regeneration of the posterior Central Nervous System. (A-F) Anti-NPF immunostaining. All samples correspond to head fragments regenerating a new posterior region. (A) Arrows point to thin fibres sprouting from the amputated nerve cords; day 1 of regeneration. (B) Transverse commissure (arrowhead) connecting the two ventral nerve cords at day 2 of regeneration. (C) Arrows point to fibres sprouting posteriorly; 3 days of regeneration. (D) A new pharynx (asterisk) develops and long longitudinal fibres sprout from the nerve cords (arrows). (E) These long sprouts form transverse commissures (arrowhead) posterior to the regenerated pharynx (asterisk) and keep growing towards the tail end (arrows). (F) As regeneration proceeds, new transverse commissures (ar rowheads) form posterior to the pharynx (asterisk). Arrows point to thin sprouts towards the tail end. Yellow arrowheads point to the differentiating new ganglia-like knots distributed along the regenerated ventral nerve cord. (G) Schematic model of the regeneration of the posterior central nervous system. Cephalic ganglia are represented in red and ventral nerve cords in green. Stage 1: 2 days of regeneration; stage 2: 3 days of regeneration; stage 3: 4 days of regeneration; stage 4: 7 days of regeneration. In all panels anterior is to the top left. Scale bar, 200 um.

posteriorly from the nerve cords (arrows in Fig. 4 C,D). At this stage a pharynx rudiment (asterisk in Fig. 4D) appears at the boundary of the blastema and stump region. Around 4 days after amputation, fine processes connected the two nerve cords (arrowhead in Fig. 4E) posterior to the differentiating pharynx (asterisk in Fig. 4E). In addition, neural sprouts projected more posteriorly (arrows in Fig. $4 \mathrm{E})$. Finally, at day 7 of regeneration, additional transverse commissures connected the nerve cords (arrowheads in Fig. 4F) posterior to the pharynx (asterisk in Fig. 4F) and

5-HT-positive cells (arrowheads in Fig. 3G) were often seen along this anti-GYRFamide-labelled commissure (arrowhead in Fig. $3 F)$. Finally, by day 5 the central neuropil, labelled with the antiGYRFamide antibody, had already regenerated its normal spongy structure (asterisks in Fig. 3H). 5-HT-positive cells (arrowheads in Fig. $3 \mathrm{H}$ ) were also detected around it.

Allatostatin-positive cells were stained with the antibody anti$5 F 10$, which in intact planarians labels individual cells in the VNCs (Cebria 2008). During regeneration, the first cells detected with this marker appear relatively late, at day 3 after amputation (arrowheads in Fig. $3 \mathrm{I})$, and become restricted to the most proximal part of the truncated VNC, as seen after double immunostaining with the anti-5-HT antibody (Fig. $3 \mathrm{~J}, \mathrm{~L}$ ).

\section{Regeneration of the posterior nerve cords}

After transverse amputation at the pre-pharyngeal level, the resulting head piece containing the original cephalic ganglia will regenerate the whole posterior body, including a new central pharynx. In order to study how the truncated nerve cords regenerate into the newly differentiated posterior regions we used the anti-NPF antibody (Fig. 4). At day 1 of regeneration, the nerve cords appeared truncated at the wound site, although fine processes sprouted from them (arrows in Fig. 4A). After 2 days of regeneration, a newly formed transverse commissure already connected the two VNCs (arrowhead in Fig. 4B). During the following 2 days, long axonal processes grow
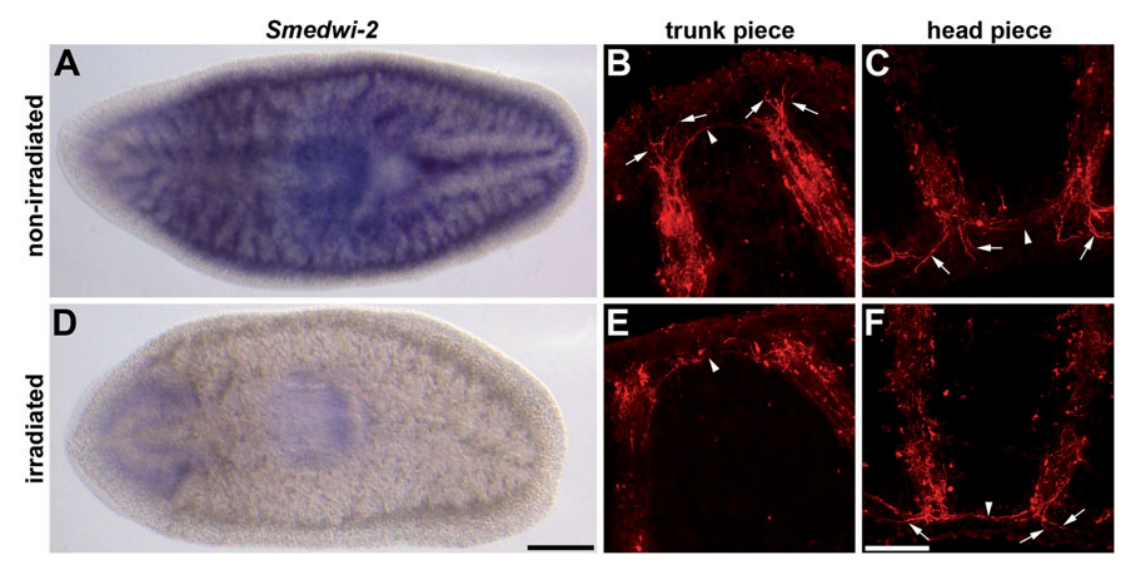

Fig. 5. Effects of irradiation on CNS regeneration (A,D). Whole mount in situ hybridizations for Smedwi-2 in non-irradiated (A) and irradiated (D) planarians. The signal in the neoblasts of the mesenchyme completely disappeared two days after irradiation (D). AntiNPF immunostainings on non-irradiated $\mathbf{( B , C )}$ and irradiated $(\mathbf{E}, \mathbf{F})$ planarians at two days of regeneration. Irradiated head pieces regenerated normally (F). Irradiated trunk pieces (E) showed abnormal regeneration compared to controls $(B)$. In $(A, D)$ anterior to the left; in the other panels, anterior to the top. Scale bars, $(A, D) 0.5 \mathrm{~mm}$; $(B, C, E, F) 100 \mu \mathrm{m}$. 
irradiated planarians. Whole-mount in situ hybridizations with the neoblast marker Smedwi-2 (Reddien et al., 2005) showed that two days after irradiation neoblasts had been already eliminated (Fig. 5 A,D). At that stage, the irradiated planarians were decapitated and allowed to regenerate for two days. Immunostainings with the anti-NPF antibody revealed that all irradiated head pieces $(n=5)$ were able to regenerate their posterior nervous system. Thus, a transverse commissure connecting the two VNCs was evident (arrowhead in Fig. 5F). Moreover, fine processes sprouted from the truncated cords (arrows in Fig. 5F), resembling very much what happened in non-irradiated regenerating head pieces (Fig. 5C). On the other hand, in irradiated trunk pieces regenerating new anterior regions a different situation was observed compared to controls (Fig. 5 B,E). All non-irradiated planarians $(n=5)$ showed a developing anterior commissure connecting the two halves of the bilateral CNS (arrowhead in Fig. 5B). Also, fine processes extended anteriorly from the truncated nerve cords (arrows in Fig. $5 B)$. In contrast, in none of the irradiated trunk pieces $(n=5)$ similar sprouts from the VNCs were observed (Fig. 5E). However, a fine commissure connecting both sides of the CNS was observed in 3 out of 5 samples (arrowhead in Fig. 5E).

\section{Distinct neuronal subpopulations detected by specific gene expression}

In addition to using different antibodies to characterize distinct neuronal subpopulations, we characterized two more neuronal cell types in $S$. mediterranea based on the expression of specific genes labelling dopaminergic and octopaminergic neurons (Fig. 6). Recently, these cell types were characterized in the planarian D. japonica through the identification of the DjTH (Nishimura et al., 2007b) and DjTBH (Nishimura et al., 2008a) genes, which encode tyrosine hydroxylase and tyramine $\beta$-hydroxylase, re- spectively. Tyrosine hydroxylase is an enzyme required in the dopamine synthesis pathway, which is highly conserved in both vertebrate and invertebrate organisms. Tyramine $\beta$-hydroxylase is involved in the synthesis of octopamine, which is known to act as a neurohormone, neurotransmitter or neuromodulator in several invertebrates (Roeder, 1999).

After cloning the respective homologues Smed-thand Smed-tbh in $S$. mediterranea, their expression patterns were determined by whole-mount in situ hybridization. In intact planarians, Smed-th was observed in isolated cells within the cephalic ganglia and along the nerve cords (Fig. 6 A-D) as well as at the tip of the head (Fig. 6A) and in the pharynx (Fig. 6 A,D). Fluorescent in situ hybridizations showed a small number of Smed-th positive cells distributed as two narrow lines of cells on the dorsal side of the cephalic ganglia (Fig. 6B). In contrast, a larger number of Smed-th cells were found throughout the ventral side of the brain (Fig. 6C). Very few Smed-th-expressing cells were detected in the VNCs (arrowheads in Fig. 6D). During anterior regeneration (Figs. 6 E-H), Smed-th-expressing cells were first detected within the blastema 2 days after amputation (Fig. 6E). At 3 days of regeneration, a large number of Smed-th cells were detected in the developing cephalic ganglia and the periphery of the head (Fig. 6F). Finally, at 7 days after amputation, when a new anterior region and cephalic ganglia have completely regenerated, the pattern of Smed-th (Figs. 6G-H) resembled that of an intact planarian.

Smed-tbh was also expressed in isolated cells throughout the CNS in intact planarians (Fig. 6I). However, unlike Smed-th, Smed-tbh was not expressed at the head tip, its expression within the pharynx was also reduced (Fig. 6I) and it was expressed in a larger number of cells along the VNC (arrows in Fig. $6 \mathrm{I}, \mathrm{L}$ ). At the level of the cephalic ganglia, Smed-tbh-positive cell populations were found dorsally (Fig. 6J) and ventrally (Fig. 6K). Compared
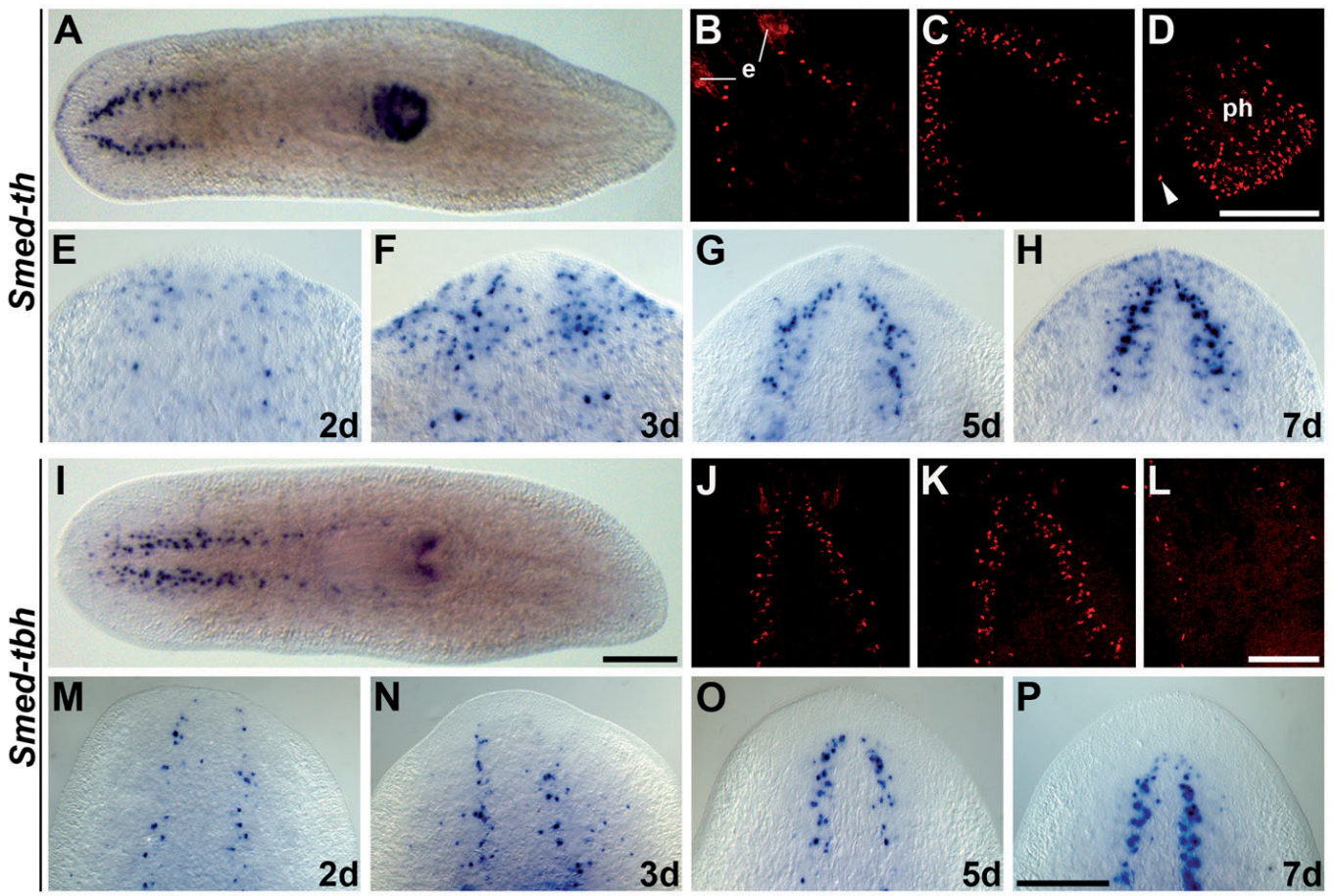

Fig. 6. Regeneration of dopaminergic and octopaminergic cell populations. Whole-mount in situ hybridizations for Smed-th (A-H) and Smed-tbh (I-P) (A-D) Smed-th expression in intact animals. (B,C) Correspond to different confocal planes of the same sample, with (B) showing the dorsal side of the brain and (C) the ventral one. (D) Individual cells within the pharynx. Arrowheads point to cells along the ventral nerve cord. (E-H) Time-course of the expression pattern of Smed-th during anterior regeneration. (I-L) Smed-tbh expression in intact planarians. $(\mathbf{J}, \mathbf{K})$ Correspond to different confocal planes of the same sample, with $(\mathbf{J})$ showing the dorsal side of the brain and (K) the ventral one. (L) Individual cells expressing Smed-tbh along the ventral nerve cord. (M-P) Time-course of the expression pattern of Smed-tbh during anterior regeneration. e, eyes, ph, pharynx. In (A, I) anterior is to the left;

in (B-D) anterior is to the top left; in the remaining panels, anterior is to the top. Days of regeneration are indicated in panels (E-H) and (M-P). GenBank accession number of Smed-tbh is JN400361. Scale bars, (A, I) 0,5 mm; (E-H, M-P) $400 \mu \mathrm{m}$, (B-D) $200 \mu \mathrm{m} ;(\mathrm{J}-\mathrm{L}) 200 \mu \mathrm{m}$. 
TABLE 1

\section{LIST OF CLASSICAL NEUROTRANSMITTER, NEUROPEPTIDE AND HORMONE RECEPTORS CHARACTERIZED BY IN SITU HYBRIDIZATION}

\begin{tabular}{|c|c|c|c|}
\hline ID number & Homologue & Reference & e-value \\
\hline $90 \_6802$ & Dopamine receptor type D2 (Apis mellifera) & NP_001011567.1 & $2 e-27$ \\
\hline 90_9109 & Serotonin receptor-like planarian receptor 4 (Dugesia japonica) & BAA22403.1 & $1 e-172$ \\
\hline 90_24753 & Peptide (allatostatin)-like receptor (Schistosoma mansoni) & XP_002572656.1 & $1 e-29$ \\
\hline v31.011509 & FMRFamide receptor (Culex quinquefasciatus) & XP_001849293.1 & $1 e-27$ \\
\hline 90_4293 & PREDICTED: similar to opioid growth factor receptor (OGFr) (Canis familiaris) & XP_543089.2 & $3 e-31$ \\
\hline Smed-crfr-1 & Corticotropin-releasing factor receptor 1 (Oryctolagus cuniculus) & NP_01156587.1 & $4 e-11$ \\
\hline v31.025532 & P2X receptor subunit (S. mansoni) & XP_002580774.1 & $3 e-149$ \\
\hline v31.003738 & P2X receptor subunit (AJ703803) (S. mansoni) & XP_002581076.1 & $8 e-104$ \\
\hline v31.027621 & Purinergic receptor $\mathrm{P} 2 \mathrm{X}$, ligand-gated ion channel, $4 \mathrm{~b}$ (Danio rerio) & NP_001119914.1 & $2 e-59$ \\
\hline v31.014493 & P2X receptor (Rhipicephalus microplus) & AD064254.1 & $2 e-69$ \\
\hline 90_9246 & PREDICTED: neuromedin-B receptor-like (Acyrthosiphon pisum) & XP_001947155.1 & $5 e-09$ \\
\hline $90 \_6303$ & Similar to neuromedin B receptor (Bos taurus) & XP_589356.2 & $6 e-25$ \\
\hline 90_28219 & Parathyroid hormone 2 receptor & AAI62580.1 & $3 e-11$ \\
\hline 90_976 & Growth hormone-inducible transmembrane protein (Osmerus mordax) & AC008873.1 & $2 e-51$ \\
\hline 90_29452 & Neuropeptide FF receptor 2 isoform 3 (Homo sapiens) & NP_001138228.1 & $2 e-09$ \\
\hline F6AJIXP02FL51R & Thyroid hormone receptor (S. mansoni) & XP_002573733.1 & $2 e-23$ \\
\hline 90_21910 & Thyroid hormone receptor interactor 11 ( $M$. musculus) & AAI58099.1 & $1 e-06$ \\
\hline 90_19836 & Adiponectin receptor 2 (Schistosoma japonicum) & CAX69605.1 & $2 e-10$ \\
\hline 90_4098 & Growth hormone secretagogue receptor (S. mansoni) & XP_002569813.1 & $7 e-36$ \\
\hline 90_11206 & Thyrotropin-releasing hormone receptor 3 (Oncorhynchus nerka) & BAI65850.1 & $7 e-26$ \\
\hline F6AJIXP02F5840 & Somatostatin receptor, putative (Aedes aegypti) & XP_001656764.1 & $9 e-14$ \\
\hline F6AJIXP02G737D & Putative neuropeptide receptor NPR1 (Girardia tigrina) & AF329279.1 & $7 e-41$ \\
\hline $90 \_6836$ & Peptide (allatostatin)-like receptor (S. mansoni) & XP_002572656.1 & $4 e-97$ \\
\hline
\end{tabular}

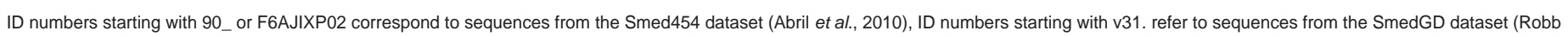
et al., 2008), and Smed-crfr-1 corresponds to a sequence directly cloned in this study.

to Smed-th-positive cells (Fig. 6A), Smed-tbh-expressing cells (Fig. 6I) appeared in more medial regions. Finally, during anterior regeneration, the first Smed-tbh cells within the blastema were detected by day 2 (Fig. 6M). In the following days, a neural network of octopamine-expressing cells became reorganized and a proper brain had differentiated 7 days after amputation (Fig. 6P).

\section{Characterization of neurotransmitter, peptide and hormone receptors}

Several studies have suggested that the nervous system may play an important role in regulating the regenerative process in planarians (reviewed in Cebrià, 2007), amphibians (Kumar et al., 2007) and Hydra (Miljkovic-Licina et al., 2007; Galliot et al., 2009). In the case of planarians, Baguña et al., (1989a) proposed a model in which neoblasts would express receptors for secreted ligands such as growth factors, neuropeptides and classical neurotransmitters that would modulate the behaviour of those neoblasts (Franquinet, 1979; Franquinet et al., 1978; Bautz and Schilt, 1986; Kreshchenko, 2008). As a first step towards validating this model, we identified 288 annotated sequences in the Smed454 dataset with significant homology to neurotransmitter, neuropeptide and hormone receptors (Abril et al., 2010). A subset of those genes (Table 1) was selected and their expression patterns were analyzed by in situ hybridization. As shown in Fig. 7, a variety of expression patterns was obtained. Some receptors, such as those for dopamine, serotonin, allatostatin, FMRFamide, opioid growth factor, somatostatin and neuropeptides were mainly expressed within the planarian CNS. Other genes showed a more ubiquitous expression that included the CNS and the mesenchyme. These included receptors for corticotropin-releasing factor, purinergic $\mathrm{P} 2 \mathrm{X}$, growth hormone-inducible transmembrane protein, neuropeptide
FF, thyroid hormone, thyroid hormone receptor interactor 11 and thyrotropin-releasing hormone. Finally, we also analyzed the expression of some of these genes during regeneration (Fig. 8). The expression of dopamine and serotonin receptors was evident within the blastema at 3 days of regeneration (arrowheads in Fig. $8 \mathrm{E}-\mathrm{F}$ ), whereas the neuropeptide FF receptor was first seen within the blastema at day 5 (arrowhead in Fig. 8K). A homologue of the thyroid hormone receptor interactor 11 was upregulated within the regenerative blastema from the first day of regeneration (arrowheads in Fig. $8 \mathrm{D}, \mathrm{H}$ ). Future experiments should help elucidating if any of these receptors are expressed in neoblasts or committed precursor cells (Cebrià, 2007). Also, further RNAi-based functional analyses should help to elucidate the function of these and other receptor homologues during planarian regeneration.

\section{Discussion}

Understanding how planarians regenerate a complete, functional CNS in just few days may provide insights into how to improve the poor regenerative capabilities shown by most animals, including mammals, and help to develop strategies to treat neurodegenerative diseases (Gentile et al., 2011). This understanding cannot be gained, however, without a clear topographical map of the distinct neuronal types within the planarian CNS. S. mediterranea is one of the main species used in planarian research. Recent studies have identified distinct neuronal populations based on immunohistochemistry with antibodies against some classical neurotransmitters and neuropeptides (Cebrià, 2008) and the characterization of the expression patterns of a large collection of genes coding for neuropeptides (Collins et al., 2010) in S. mediterranea. In this study, some of these markers and new ones have been used to 
characterize how the planarian CNS regenerates.

During anterior regeneration, planarians have to make a new brain at the same time that the truncated VNCs grow into the blastema, below the differentiating cephalic ganglia. Reuter et al., (1996) studied the regeneration of the CNS in the planarian Dugesia tigrina using anti-5-HT and anti-NPF antibodies. They proposed that the regeneration of the new cephalic ganglia involves two main steps. First, processes from the truncated VNC sprout anteriorly

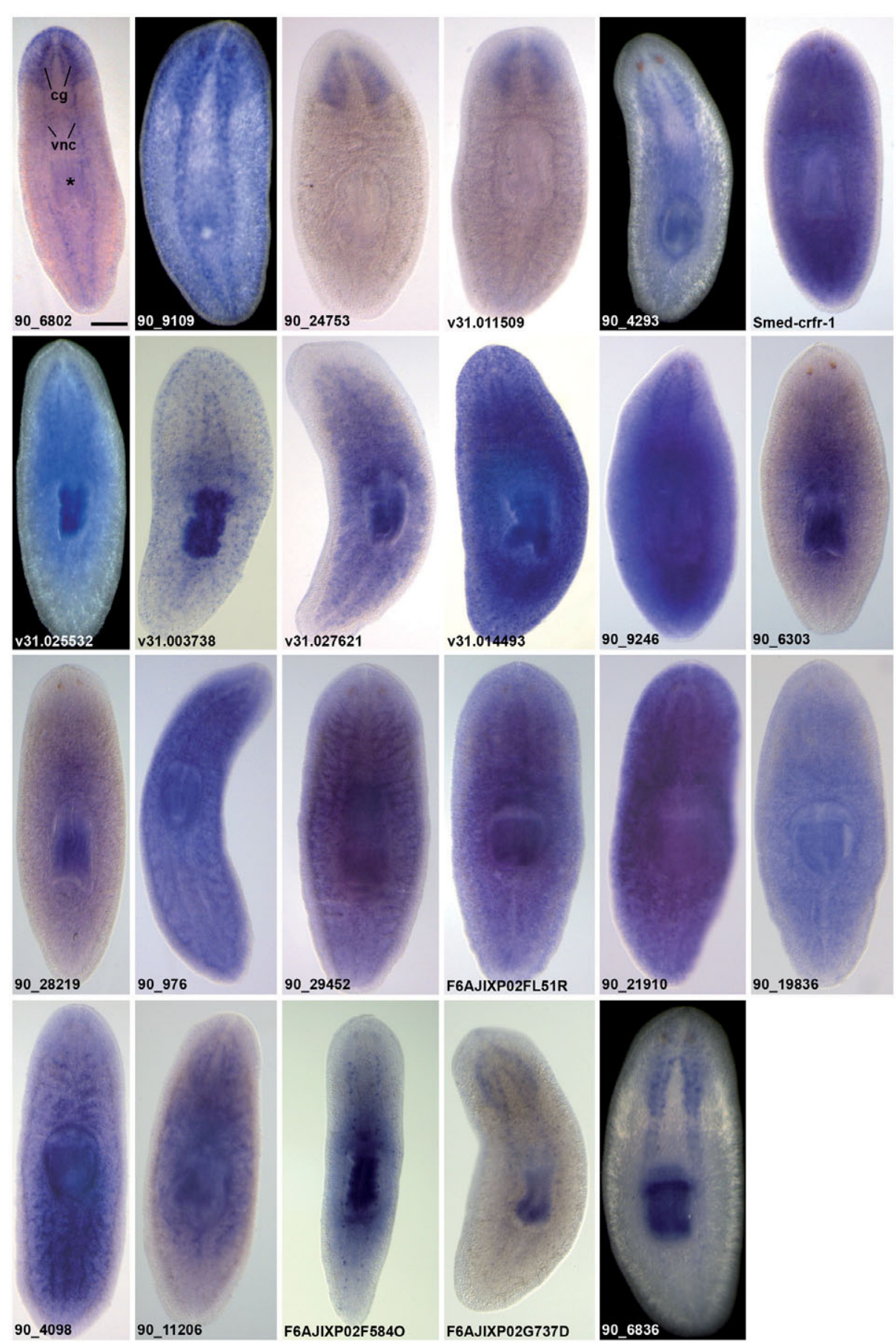

Fig. 7. Expression patterns of neurotransmitter, neuropeptide and hormone receptors in intact planarians. Whole-mount in situ hybridizations for the receptors described in Table 1. cg, cephalic ganglia; vnc, ventral nerve cords; *, pharynx. In all panels anterior is to the top. GenBank accession number for Smed-crfr-1 is JN400362. Scale bar, $0.5 \mathrm{~mm}$. and bend contralaterally, crossing the midline and defining the position of the arch-shaped commissure that will connect the left and right cephalic ganglia (1-2 days of regeneration). In a second stage, new neurons would differentiate in front of this commissure and their fibres would fasciculate with the existing ones, allowing the growth of the neuropil (3-5 days of regeneration) (Reuter et al., 1996). More recently, it has been proposed that the primordia of the new cephalic ganglia appear within the blastema at day 1 of regeneration before any axonal sprouting from the truncated VNCs is observed (Cebrià et al., 2002a; Agata and Umesono, 2008). Later on, fibres sprouting from those VNCs would enter the blastema and somehow connect with the developing cephalic ganglia. However, in the absence of specific markers for the cell bodies and axonal fibres of individual neurons from either the brain or the VNC, it is difficult to understand the temporal and spatial dynamics of the reconstruction of these closely connected structures during regeneration.

Taking into account those previous models and the results obtained here, an updated proposal for planarian anterior CNS regeneration is summarized in Fig. 2V. At day 1 of regeneration, an accumulation of positive cells for 5-HT and GYRFamide is detected around the ends of the truncated VNC (Fig. 3 $A, E)$. Positive cells for NPF and FMRFamide are observed at the same location by day 2-3 of regeneration (Fig. 2D; M). This agrees with previous observations in $D$. tigrina in which 5-HT-positive cells were also seen around the cut ends of the VNC (Reuter et al., 1996). Around 2-3 days of regeneration, two types of commissures connecting the left and right CNS are observed. A relatively thick commissure is seen with antibodies against NPF (arrowhead in Fig. 2E), FMRFamide (arrowhead in Fig. 2O), 5-HT (arrowhead in Fig. 3B) and GYRFamide (arrowhead in Fig. 3F) in a more dorsal region, where the primordia of the cephalic ganglia are being formed. Because of its position and the fact that it apparently projects from the new brain primordia, this commissure would correspond to the anterior commissure connecting the left and right cephalic ganglia in adult planarians. Immunohistochemistry with the anti-NPF antibody also uncovers fine fibres connecting the left and right sides of the CNS. These fibres (arrows in Fig. 2 E,G,I) appear close to the brain commissure and seems to originate from sprouts from the VNCs that project beyond the developing cephalic ganglia and then bend contralaterally (arrows in Fig. 2 G,I). Interestingly, in the intact CNS of model species such as $S$. mediterranea and $D$. japonica, the VNCs below the brain never pass above it (Agata et al., 1998; Cebrià 2008). However, during 

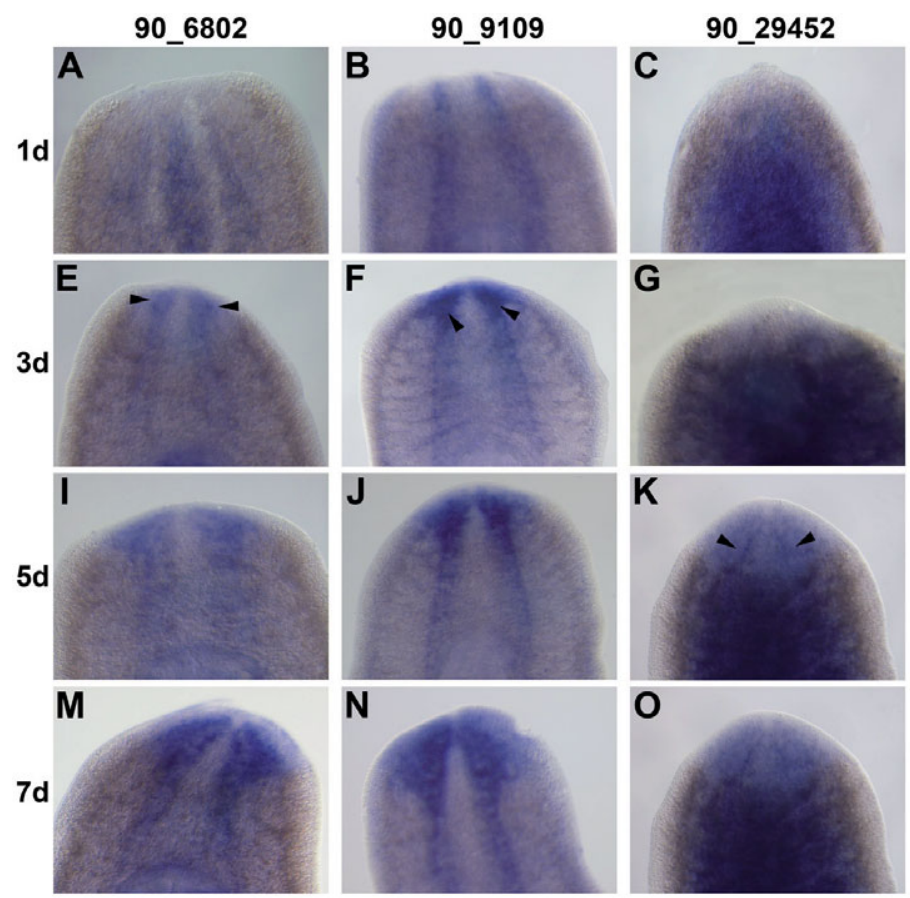

regeneration, NPF-positive fibres sprouting from the VNCs clearly reach regions more anterior to the developing cephalic ganglia. As regeneration proceeds, those transverse fibres appear to project along the anterior commissure (arrows in Fig. 2I). Further analyses should try to elucidate whether those transverse fibres from the VNCs have a role during regeneration, such as defining the borders of the brain commissure. Also, at day 3 of regeneration, 5-HT-expressing cells are seen all along the brain commissure labelled with the anti-GYRFamide antibody (arrowheads in Fig. $3 G)$. This is in agreement with previous observations in $D$. tigrina (Reuter et al., 1996). Taken together, even though previous studies suggested that the first neuropil stems from fibres emerging from the ends of the truncated nerve cords (Reuter et al., 1996), the data presented here suggest that the anterior commissure would originate also from fibres sprouting from the brain primordia at very early stages of regeneration. However, definitive proof will not come until we are able to unambiguously distinguish between the fibres sprouting from cells of the VNCs and the cephalic ganglia.

The dynamics of CNS regeneration is clearer during posterior regeneration, as only the VNCs are involved. As summarized in Fig. $4 \mathrm{G}$, at 2 days of regeneration, the truncated nerve cords become connected by a transverse commissure. Next, fibres sprouting from those cut ends of the nerve cords project posteriorly a long distance (arrows in Fig. 4 C-D) before sending out a new transverse commissure. This new commissure always appears posterior to the new pharynx (asterisks in Fig. 4 D-E) that develops at the border of the blastema/stump. From that stage, the nerve cords appear to grow from additional sprouts towards the posterior end (arrows in Fig. 4 E-F) and transverse commissures (arrowheads in Fig. 4 $\mathrm{E}-\mathrm{F})$ also develop in an anterior-to-posterior direction.

Remarkably, posterior regeneration of the VNCs is not blocked after irradiation (Fig. 5F), suggesting that either those early stages of neural regeneration depend on sprouts extending directly from the truncated axons of the VNC neural cells or they depend on the presence of post-mitotic neural precursors that can initiate
$90 \_21910$
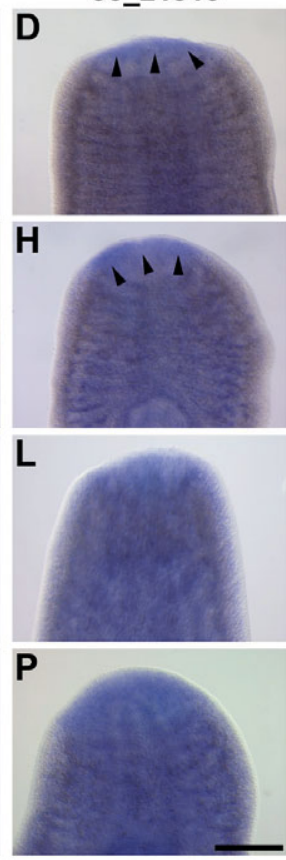

Fig. 8. Expression patterns of neurotransmitter, neuropeptide and hormone receptors during anterior regeneration. Time-course of the expression of dopamine receptor (90_6802), serotonin receptor (90_9109), neuropeptide FFreceptor(90_29452) and thyroid hormone receptor interactor 11 (90_21910) during regeneration of a new head. Days of regeneration are indicated in the left column. In all panels, anterior is to the top. Scale bar, $400 \mu \mathrm{m}$.

the regeneration process. Further studies using specific markers not yet available should help determining the origin of this regenerated posterior CNS. In contrast, anterior neural regeneration is clearly affected after irradiation. Thus, no sprouts from the truncated VNCs extend anteriorly and only in 3 out of 5 samples did some fine processes from a transverse commissure. This raises the question of why there are no sprouts extending from the amputated nerve cords. One possibility could be that different signals function during anterior and posterior regeneration to promote neural regeneration. Our results suggest that in the case of anterior regeneration such signals would depend on the presence of neoblasts or their descendents.

In summary, we have characterized the regeneration of the planarian CNS at the cellular level through labelling with distinct specific antibodies. Also, we have described novel markers for specific neuronal populations in S. mediterranea that can be useful not only to study regeneration per se but also to characterize future RNAi phenotypes. The combined study of these neuronal factors and their receptors should help to better understand neural regeneration and to characterize the function of additional neurotransmitters, peptides and hormones during planarian regeneration.

\section{Materials and Methods}

\section{Planarians and culture conditions}

S. mediterranea from the clonal line $\mathrm{BCN}-10$ were used for all experiments. Animals were maintained at $20^{\circ} \mathrm{C}$ in a $1: 1(\mathrm{v} / \mathrm{v})$ mixture of distilled water and tap water treated with AquaSafe (TetraAqua). Planarians were fed with beef liver and starved for at least 1 week before experiments. For irradiation experiments planarians were irradiated at a dose of 100 Gy and amputated two days later to be sure that all the neoblasts had been eliminated.

\section{Whole-mount immunohistochemistry}

Depending on the primary antibody used, animals were fixed in two ways: for anti-5HT, anti-GYRFamide and anti-allatostatin (5F10) antibodies, animals were fixed with $4 \%$ paraformaldehyde as previously described (Cebria, 2008), and for anti-neuropeptide $F$ and FMRFamide, animals were killed in 5\% NAC (N-acetyl cysteine) in PBS for $8 \mathrm{~min}$ at room temperature (RT) and fixed in $4 \%$ formalin in PBTx (PBS + 0.3\% Triton X-100) for 30 min at RT (as described in Pearson et al., 2009). After that, samples were treated in $50 \% \mathrm{MeOH}$ in PBTx for $10 \mathrm{~min}$ at RT, $100 \% \mathrm{MeOH}$ for $10 \mathrm{~min}$ at $\mathrm{RT}$ and stored at least 2 hours in $\mathrm{MeOH}$ at $-20^{\circ} \mathrm{C}$. Samples were then bleached and the protocol continued as described previously (Cebrià, 2008). Primary antibodies were used at the following dilutions: 5 -HT (Sigma, ref. S5545), 1:1,000; GYRFamide (Johnston et al., 1996), 1:1000; 5F10 (Developmental Studies Hybridoma Bank), 1:2; neuropeptide F (Maule et 
al., 1992), 1:1000; and FMRFamide (DiaSorin, ref. 20091), 1:500. Alexa 488-conjugated goat anti-mouse and Alexa 568-conjugated goat anti-rabbit secondary antibodies (Molecular Probes) were used at a 1:400 and 1:1000 dilutions, respectively. Samples were mounted in SlowFade ${ }^{\circledR}$ Gold antifade reagent (Invitrogen). Confocal laser scanning microscopy was performed with Leica TCS-SPE and a Leica SP2 microscopes and then images were processed using Image $\mathrm{J} 1.43 \mathrm{~m}$.

\section{Whole-mount in situ hybridization}

Specific primers were used to amplify the genes used in this study from cDNA. Whole-mount in situ hybridizations were performed as previously described (Umesono et al., 1997; Molina et al., 2007) using an Intavis InsituPro hybridization robot. For fluorescence in situ hybridization with Smed-th and Smed-tbh riboprobes, samples were developed as previously described (Cebrià et al., 2007, Pearson et al., 2009) using Tyramide Signal Amplification (Perkin Elmer) according to the manufacturer's instructions. All samples were observed through a Leica MZ16F stereomicroscope and images from representative organisms for each experiment were captured with a Prog Res ${ }^{\circledR} \mathrm{C} 3$ camera (Jenoptik). Confocal laser scanning microscopy was performed with Leica SP2 and SPE microscopes.

\section{Acknowledgements}

We would like to thank Aaron C. Maule for the anti-NPF and antiGYRFamide antibodies. Anti-5F10 (anti-allatostatin) monoclonal antibody was obtained from the Developmental Studies Hybridoma Bank, University of lowa. We thank lain Patten for advice on English style in a version of the manuscript. S.F. is supported by an FPI fellowship (MICINN, Spain). S.B. is supported by an APIF fellowship (University of Barcelona). F.C. is a Ramón y Cajal Researcher (MICINN, Spain). This work was supported by grants BFU2008-00710 (MICINN, Spain) and 2009SGR1018 (AGAUR, Generalitat de Catalunya) to F.C.

\section{References}

ABRIL, J. F., CEBRIÀ, F., RODRIGUEZ-ESTEBAN, G., HORN, T., FRAGUAS, S. CALVO, B., BARTSCHERER, K. and SALO, E. (2010). Smed454 dataset: unravelling the transcriptome of Schmidtea mediterranea. BMC Genomics 11: 731.

AGATA, K., SOEJIMA, Y., KATO, K., KOBAYASHI, C., UMESONO, Y. and WATANABE, K. (1998). Structure of the planarian central nervous system (CNS) revealed byneuronal cell markers. Zoolog Sci 15: 433-440.

AGATA, K. and UMESONO, Y. (2008). Brain regeneration from pluripotent stem cells in planarian. Philos Trans R Soc Lond B Biol Sci 363: 2071-2078.

BAGUÑÀ, J., SALÓ, E. and AULADELL, C. (1989a). Regeneration and pattern formation in planarians. III. Evidence that neoblasts are totipotent stem cells and the source of blastema cells. Development 107: 77-86.

BAGUÑÀ, J., SALO, E. and ROMERO, R. (1989b). Effects of activators and antagonists of the neuropeptides substance $\mathrm{P}$ and substance $\mathrm{K}$ on cell proliferation in planarians. Int J Dev Biol 33: 261-266

BAUTZ, A. and SCHILT, J. (1986). Somatostatin-like peptide and regeneration capacities in planarians. Gen Comp Endocrinol 64: 267-272

CEBRIÀ, F., NAKAZAWA, M., MINETA, K., IKEO, K., GOJOBORI, T. and AGATA, K. (2002a). Dissecting planarian central nervous system regeneration by the expression of neural-specific genes. Dev Growth Differ 44: 135-146.

CEBRIÀ, F., KUDOME, T., NAKAZAWA, M., MINETA, K., IKEO, K., GOJOBORI, T. and AGATA, K. (2002b). The expression of neural-specific genes reveals the structural and molecular complexity of the planarian central nervous system. Mech Dev 116: 199-204.

CEBRIÀ, F. (2007). Regenerating the central nervous system: how easy for planarians! Dev Genes Evol 217: 733-748.

CEBRIÀ, F., GUO, T., JOPEK, J. and NEWMARK, P.A. (2007). Regeneration and maintenance of the planarian midline is regulated by a slit orthologue. Dev Biol 307: 394-406.

CEBRIÀ, F. (2008). Organitzation of the nervous system in the model planarian Schmidtea mediterranea: an immunocytochemical study. Neurosci Res61:375-384.

CEBRIÀ, F. and NEWMARK, P. A. (2005). Planarian homologs of netrin and netrin receptor are required for proper regeneration of the central nervous system and the maintenance of nervous system architecture. Development 132: 3691-3703.

CEBRIÀ, F. and NEWMARK, P. A. (2007). Morphogenesis defects are associated with abnormal nervous system regeneration following roboA RNAi in planarians. Development 134: 833-837.

COLLINS, J. J., 3rd, HOU, X., ROMANOVA, E. V., LAMBRUS, B. G., MILLER, C M., SABERI, A., SWEEDLER, J. V. and NEWMARK, P. A. (2010). Genome-wide analyses reveal a role for peptide hormones in planarian germline development. PLOS Biol 8: e1000509.

FRAGUAS, S., BARBERAN, S. and CEBRIA, F. (2011) EGFR signaling regulates cell proliferation, differentiation and morphogenesis during planarian regeneration and homeostasis. Dev Biol 354: 87-101.

FRANQUINET, R., LE MOIGNE, A. and HANOUNE, J. (1978). The adenylate cyclase system of planaria Polycelis tenuis: activation by serotonin and guanine nucleotides. Biochim Biophys Acta 539: 88-97.

FRANQUINET, R. (1979). The role of serotonin and catecholamines in the regeneration of the planaria Polycelis tenvis. J Embryol Exp Morphol 51: 85-95.

FRANQUINET, R. and LE MOIGNE A. (1979). Relation entre les variations des taux de sérotonine et d'AMP cyclique au cors de la régénération d'une planaire. Biol. Cell 34: 71-76.

FUSAOKA, E., INOUE, T., MINETA, K., AGATA, K. and TAKEUCHI, K. (2006). Structure and function of primitive immunoglobulin superfamily neural cell adhesion molecules: a lesson from studies on planarian. Genes to Cells 11: 541-555.

GALLIOT, B., QUIQUAND, M., GHILA, L., de ROSA, R., MILJKOVIC-LICINA, M. and CHERA, S. (2009). Origins of neurogenesis, a cnidarian view. Dev Bio/332: 2-24.

GENTILE, L., CEBRIA, F. and BARTSCHERER, K. (2011). The planarian flatworm: an in vivo model for stem cell biology and nervous system regeneration. Dis Model Mech 4: 12-19.

HIGUCHI, S., HAYASHI, T., TARUI, H., NISHIMURA, O., NISHIMURA, K., SHIBATA, N., SAKAMOTO, H. and AGATA, K. (2008). Expression and functional analysis of musashi-like genes in planarian CNS regeneration. Mech Dev 125: 631-645.

INOUE, T., HAYASHI, T., TAKECHI, K. and AGATA, K. (2007). Clathrin-mediated endocytic signals are required for the regeneration of, as well as homeostasis in, the planarian CNS. Development 134: 1679-1689.

JOHNSTON, R.N., SHAW, C., HALTON, D.W., VERHAERT, P., BLAIR, K.L., BRENNAN, G.P., PRICE, D.A. and ANDERSON, P.A.V. (1996). Isolation, localisation and bioactivity of the FMRFamide-related neuropéptido GYRFamide and YIRFamide from the marine turbellarian Bdelloura candida. J Neurochem 67: 814-821.

KOBAYASHI, C., SAITO, Y., OGAWA, K. and AGATA, K. (2007). Wnt signaling is required for antero-posterior patterning of the planarian brain. Dev Biol306: 714-724.

KRESHCHENKO, N. D. (2008). Functions of flatworm neuropeptides NPF, GYIRF and FMRF in course of pharyngeal regeneration of anterior body fragments of planarian, Girardia tigrina. Acta Biol Hung 59(Suppl): 199-207.

KRESHCHENKO, N. D., SEDELNIKOV Z, SHEIMAN IM, REUTER M, MAULE AG, GUSTAFSSON MK. (2008). Effects of neuropeptide F on regeneration in Girardia tigrina (Platyhelminthes). Cell Tissue Res 331: 739-750

KUMAR, A., GODWIN, J. W., GATES, P. B., GARZA-GARCIA, A. A. and BROCKES, J. P. (2007). Molecular basis for the nerve dependence of limb regeneration in an adult vertebrate. Science 318: 772-777.

MAULE, A. G., SHAW, C., HALTON, D. W., BRENNAN, G. P., JOHNSTON, C. F. and MOORE, S. (1992). Neuropeptide F (Moniezia expansa): localization and characterization using specific antisera. Parasitology 105: 505-512.

MILJKOVIC-LICINA, M., Chera, S., GHILA, L., GALLIOT, B. (2007) Head regeneration in wild-type hydra requires de novo neurogenesis. Development 134: 1191-1201.

MINETA, K., NAKAZAWA, M., CEBRIÀ, F., IKEO, K., AGATA, K. and GOJOBORI, T. (2003). Origin and evolutionary process of the CNS elucidated by comparative genomics analysis of planarian ESTs. Proc Natl Acad Sci USA 100: 7666- 7671.

MOLINA, MD., SALÓ, E. and CEBRIÀ, F. (2007). The BMP pathway is essential for re-specification and maintenance of the dorsoventral axis in regenerating planarians. Dev Biol 311: 79-94.

NISHIMURA, K., KITAMURA, Y., INOUE, T., UMESONO, Y., YOSHIMOTO, K., TAKEUCHI, K., TANIGUCHI, T. and AGATA, K. (2007a). Identification and distribution of tryptophan hydroxylase (TPH)-positive neurons in the planarian Dugesia japonica. Neurosci Res 59: 101-106.

NISHIMURA, K., KITAMURA, Y., INOUE, T., UMESONO, Y., SANO, S., YOSHIMOTO, 
K., INDEN, M., TAKATA, K., TANIGUCHI, T., SHIMOHAMA, S., AGATA, K. (2007b). Reconstruction of dopaminergic neural network and locomotion function in planarian regenerates. Dev Neurobiol 67: 1059-1078.

NISHIMURA, K., KITAMURA, Y., INOUE, T., UMESONO, Y., YOSHIMOTO, K., TANIGUCHI, T. and AGATA, K. (2008a). Characterization of tyramine beta-hydroxylase in planarian Dugesia japonica: cloning and expression. Neurochem Int53: 184-192.

NISHIMURA, K., KITAMURA, Y., UMESONO, Y., TAKEUCHI, K., TAKATA, K., TANIGUCHI, T. and AGATA, K. (2008b). Identification of glutamic acid decarboxylase gene and distribution of GABAergic nervous system in the planarian Dugesia japonica. Neuroscience 153: 1103-1114.

NISHIMURA, K., KITAMURA, Y., AGATA, K. (2008c). Molecular mechanism of brain regeneration and reconstruction of dopaminergic neural network in planarians. Brain Nerve 60: 307-317.

OKAMOTO, K., TAKEUCHI, K. and AGATA, K. (2005). Neural projections in planarian brain revealed by fluorescent dye tracing. Zoolog Sci 22: 535-546.

PEARSON, B.J., EISENHOFFER, G.T., GURLEY, K.A., RINK, J.C., MILLER, D.E. and SÁNCHEZ-ALVARADO, A. (2009). Formaldehyde-based whole-mount in situ hybridization method for planarians. Dev Dyn 238: 443-450.

ROEDER, T. (1999). Octopamine in invertebrates. Prog Neurobiol. 59: 533-561.

REDDIEN, P.W., OVIEDO, N.J., JENNINGS, J.R., JENKIN, J.C. and SÁNCHEZ ALVARADO, A. (2005). SMEDWI-2 is a PIWI-like protein that regulates planarian stem cells. Science 310: 1327-1330.

REUTER, M., SHEIMAN, I.M., GUSTAFSSON, M.K.S., HALTON, D.W., MAULE, A.G. SHAW, C. (1996). Development of the nervous system in Dugesia tigrina during regeneration after fission and decapitation. Invert. Reprod. Dev. 29: 199-211.

UMESONO, Y., WATANABE, K. and AGATA, K. (1997). A planarian orthopedia homolog is specifically expressed in the branch region of both the mature and regenerating brain. Dev Growth Differ 39: 723-727.

UMESONO, Y., WATANABE, K. and AGATA, K. (1999). Distinct structural domains in the planarian brain defined by the expression of evolutionarily conserved homeobox genes. Dev Genes Evol 209: 31-39.

WAGNER, D. E., WANG, I. E. and REDDIEN, P. W. (2011). Clonogenic neoblasts are pluripotent adult stem cells that underlie planarian regeneration. Science 332: 811-816. 


\section{Further Related Reading, published previously in the Int. J. Dev. Biol.}

Diverse miRNA spatial expression patterns suggest important roles in homeostasis and regeneration in planarians Cristina González-Estévez, Varvara Arseni, Roshana S. Thambyrajah, Daniel A. Felix and A. Aziz Aboobaker Int. J. Dev. Biol. (2009) 53: 493-505

Planarian regeneration: achievements and future directions after 20 years of research Emili Saló, Josep F. Abril, TeresaAdell, Francesc Cebriá, Kay Eckelt, Enrique Fernández-Taboada, Mette Handberg-Thorsager, Marta Iglesias, M Dolores Molina and Gustavo Rodríguez-Esteban Int. J. Dev. Biol. (2009) 53: 1317-1327

Two $\mathrm{msh} / \mathrm{msx}$-related genes, Djmsh1 and Djmsh2, contribute to the early blastema growth during planarian head regeneration

Linda Mannini, Paolo Deri, Vittorio Gremigni, Leonardo Rossi, Alessandra Salvetti and Renata Batistoni

Int. J. Dev. Biol. (2008) 52: 943-952

Expression of DjXnp, a novel member of the SNF2-like ATP-dependent chromatin remodelling genes, in intact and regenerating planarians

Leonardo Rossi, Paolo Deri, Ilaria Andreoli, Vittorio Gremigni, Alessandra Salvetti and Renata Batistoni

Int. J. Dev. Biol. (2003) 47: 293-298

Planarian pharynx regeneration revealed by the expression of myosin heavy chain-A Tomoko Sakai, Kentaro Kato, Kenji Watanabe and Hidefumi Orii

Int. J. Dev. Biol. (2002) 46: 329-332

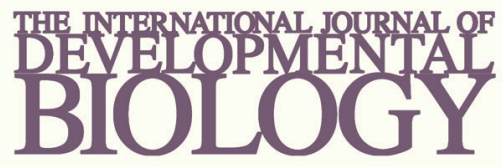

Volume 54 Nos. $6 / 7$
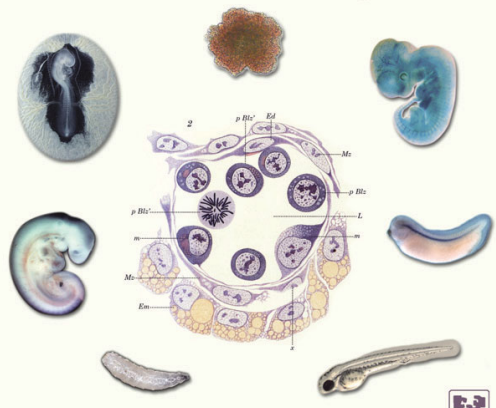

Developmental Hematopoiesis
5 yr ISI Impact Factor $(2010)=2.961$

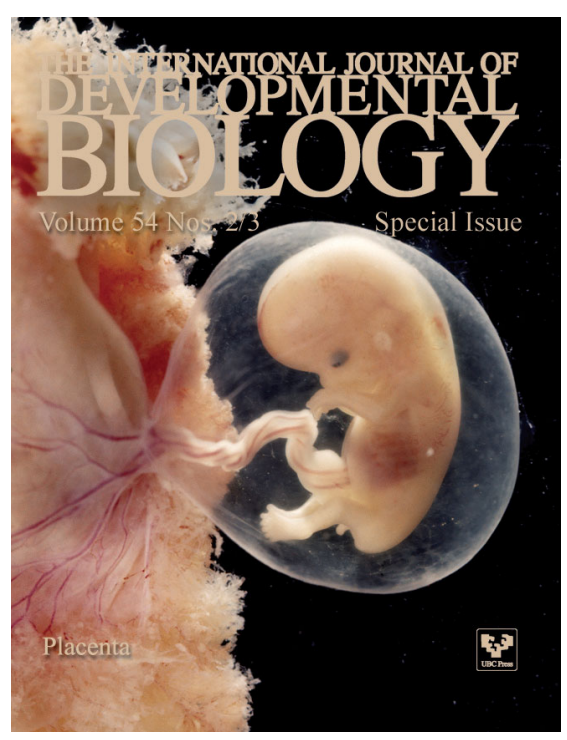

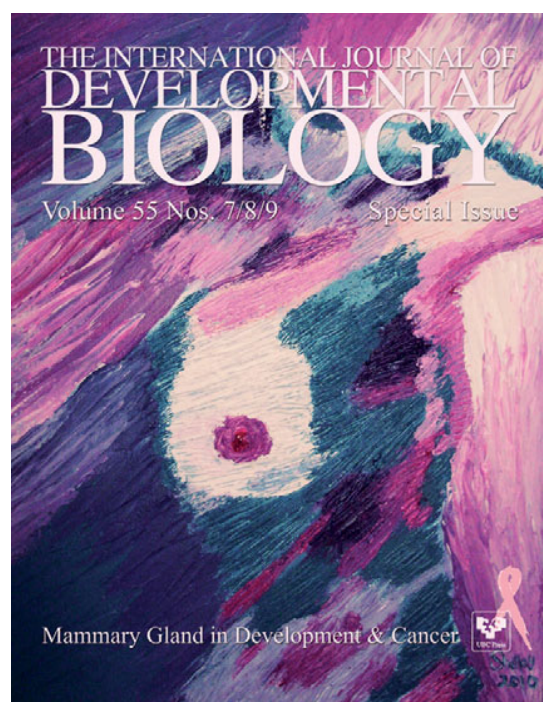

THE INTERNATIONAL JOURNAL OF DEVELOPMIENTAL BIOLOGY

Volume 55 Nos. $4 / 5$

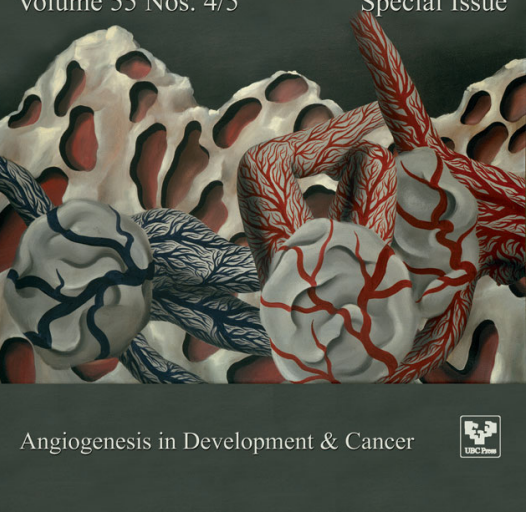

